\title{
Raising Rivals' Fixed Costs
}

\section{MORTEN HVIID and MATTHEW OLCZAK}

\begin{abstract}
This article demonstrates that raising fixed costs can serve as a credible mechanism for a well placed firm to exclude its rivals. We identify a number of credible avenues, such as increased regulation, vexatious litigation and increased prices for essential inputs, through which such a firm can raise fixed costs. We show that for a wide range of oligopoly models this may be a profitable strategy, even if the firm's own fixed costs are affected as much (or even more) than its rivals and even if it is less efficient. The resulting reduction in the number of firms in the market is detrimental to consumer welfare and hence worthy of scrutiny by competition and regulatory authorities.
\end{abstract}

Key Words: Raising Rivals' Costs; Fixed Costs; Exclusion; Entry Deterrence; Monopolisation.

JEL Classifications: L13, L41, L51.

\section{Introduction}

Lately the application of the label "raising rivals' costs" (RRC) to strategic behaviour has been widened considerably to cover most of the monopolisation strategies dealt with in the US under section of the Sherman Act and the exclusionary abuses dealt with in the EU under the abuse of dominance (Article 102TFEU). This follows a recognition that the effect of most exclusionary strategies is to raise costs of rivals or potential rivals. Because these strategies force them to look elsewhere for inputs or outlets for their products, they become less competitive and in extreme cases choose to exit or not to enter the market.

Competition policy has largely been focused on strategies such as exclusionary conduct or margin squeezes, which aim to raise rivals' marginal

We thank Sven Gallasch, Andrew Gavil, Georg von Graevenitz, Greg Shaffer, Christopher Wilson and the two anonymous referees for helpful comments.

This work was supported by the UK Economic and Social Research Council [grant number RES-578-28-0002]. 
costs. This is in line with the economics literature that generally gives marginal costs pre-eminence above fixed costs since these directly affect firms incentives regarding pricing and output decisions. In line with this, much of the traditional theoretical literature on RRC (see the section on related literature) has focused on variable costs with essential input prices and regulation, the two long-standing examples of means through which costs can be raised. We argue that in both of these cases such strategies may often predominantly affect fixed costs. Furthermore, we outline a range of other ways in which a firm could raise the fixed costs of all firms within the industry.

This paper is the first to formally establish the anti-competitive effects of such a fixed-cost-raising strategy within a fully specified oligopolistic framework. Recalling that fixed costs affect the participation constraint of a firm when these costs are not incurred if the firm exits the industry, ${ }^{1}$ we demonstrate that in a wide range of oligopoly models raising fixed costs can serve as a credible mechanism for a well placed firm to exclude its rivals. This can be achieved by either forcing a rival to exit the market or by deterring a rival's entry; henceforth, we will use "exclusion" to refer to either case. Our findings generalise the insights which can be gained from considering the strategic raising of fixed costs in the model by Dasgutpa and Stiglitz (1988), who consider entry under homogenous Bertrand competition when fixed costs are present, although not as a result of strategic behaviour.

We show that raising fixed costs can be a profitable strategy for a firm even if its fixed costs are affected as much as (or even more than) its rivals. This is in contrast to strategies that increase variable costs which, typically, are not profitable if the strategy raises the firm's own costs by at least as much as its rivals (see Mason, 2002). In addition, we show that the perpetrator of a fixedcost-raising strategy can be less efficient than its excluded rivals and we consider the possibility that its beneficial position may arise from a first-mover advantage in its output decision.

From a policy perspective the main message of this article is that many cost-raising strategies, even if they do not affect marginal costs, can have significant anti-competitive effects and be detrimental to consumer welfare; hence, the nature of the costs cannot be used as a filter to determine which cost-raising strategies should be subject to scrutiny by competition and regulatory authorities.

The remainder of the paper is organised as follows. In the second section we summarise the related literature and highlight a range of examples of ways in which firms could raise fixed costs. In the third section we present our general model which provides a general sufficient condition for a fixedcost-raising strategy to be profitable and develops a number of implications from this. In the fourth section we apply the general model to a number of specific oligopoly models. This allows us to further illustrate the range of levels of the fixed costs for which raising fixed costs is a profitable strategy and to extend the analysis by allowing for the firm that raises fixed costs to have higher marginal costs and to have a first-mover advantage in the product market. Finally, we conclude the paper with a discussion on the welfare and policy implications of the analysis. 


\section{Related Literature}

The traditional theoretical literature on RRC has focused on raising variable costs. Williamson (1968) provided one of the earliest examples of a RRC strategy. This was based on raising the costs of essential inputs and more specifically concerned the negotiation of higher wages for key personnel. As discussed in Appendix 1, this was motivated by a case brought against a US mining firm; however, it was not until Salop and Scheffman $(1983,1987)$ that the first formal model of RRC emerged. They argued that, unlike predation, a strategy of raising rivals' variable costs was more credible, did not require the rival to exit the market and allowed short-run gains. Their model used a dominant firm, competitive fringe set-up to show how this strategic RRC could be achieved. It showed that an RRC strategy is profitable if the increase in costs leads to an increase in the dominant firm's residual demand which exceeds the shift in its average cost curve. They showed that this may have a negative or a positive effect on the fringe's profit and on consumer welfare. They then applied their model to a number of settings, in particular to raising the cost of an essential input.

Oster (1982) was the first to formalise the idea that a firm might be able to use regulation strategically to raise variable costs. She offered the example of US brand name drug producers in the 1970s lobbying for regulation to disadvantage generic producers. An extensive and well established literature on lobbying for regulation followed; see, for example, Michaelis (1994), where two political parties compete for campaign contributions from firms that are subject to regulation.

In Appendix 1 we discuss further these two classic examples of using essential input prices and regulation as means to RRC. We argue that in both cases such strategies will often predominantly affect fixed rather than variable costs. In addition, we add a further three ways in which one firm can raise the fixed costs of all firms in the industry. These are, firstly, vexatious litigation where the primary aim is to disadvantage the defendant rather than right a wrong, secondly, situations such as slotting allowances and land banks of retail sites where there is competition for capacity and finally, the use of advertising to blur the message of a rival. As discussed in the appendix, these strategies also predominantly affect fixed costs and, taken together, all five cover a significant range of sectors of the economy. The fact that their impact is predominantly on fixed costs means that these examples do not fit well with the previous RRC literature described above.

A number of previous papers have focused on the impact of fixed costs on competition. Firstly, Dasgupta and Stiglitz (1988) consider sequential entry decisions in a homogeneous goods Bertrand model in the presence of fixed costs. They show that with any positive level of fixed costs (not necessarily resulting from strategic behaviour) the outcome is a monopoly. In the section on Bertrand competition with homogenous products, we relate this specific setting to our general model with fixed costs arising from strategic behaviour. Secondly, Rogerson (1984) uses a simple example to show that where entrants are non-strategic "quantity takers", an incumbent with a first-mover advantage can profitably deter entry by raising fixed costs. Finally, McChesney (1997) uncovers industry preferences for regulation, which raises the fixed costs by considering aggregate supply functions rather than strategic firm behaviour. 
The aggregate supply function shifts up and left when an increase in fixed costs causes a reduction in the number of firms and therefore the market clearing price will increase. The resulting gain in profit may be sufficient to compensate for the increase in fixed costs. In contrast to our paper, none of these contributions model the individual incentives of firms, nor the mechanism through which a cost-raising strategy could have the desired effect.

\section{General Model}

In our general model we will allow for an endogenously determined number of symmetric firms to compete under a wide range of oligopoly models including Cournot competition and Bertrand competition with differentiated goods. This allows us to derive a general sufficient condition for a "raising fixed costs" strategy to be profitable. In the fourth section we focus on Bertrand competition with homogenous products and Cournot duopoly competition. This allows us to further illustrate the scope for fixed-cost-raising strategies and to extend the analysis by allowing for asymmetry between firms in marginal costs and through sequential moves in output decisions.

\subsection{Set-up and Assumptions}

Whilst firms are initially otherwise identical, we assume that one (henceforth denoted firm 1) of the firms has the ability to take an action which raises the fixed costs of all firms before they simultaneously make their pricing or output decisions. As the examples in Appendix illustrate, there are several ways in which a firm can find itself in this position. The obvious cases are where a single firm faces one or more potential entrants. In other cases, the opportunity to engage in cost-raising behaviour may be limited to a specific firm or firms. One example is lobbying where one might reasonably think that domestic firms have a strong advantage. This may also arise through design, for example in planning patent thickets with vexatious litigation in mind. Such advantages can also arise from idiosyncrasies in the market, for example from the way supermarkets structure a sequential set of auctions for shelf space. Finally, the opportunity to raise costs may arise purely fortuitously, for example a firm's patent portfolio may also serendipitously facilitate vexatious litigation.

In addition, in keeping with the examples discussed in detail in Appendix 1, we make a number of further assumptions. Firstly, the fixed costs are all avoidable for a firm which decides not to produce, and the source of the increase in fixed costs is common knowledge. Secondly, the action is initially assumed to raise all firms' fixed costs equally and the resulting magnitude of the increase is common knowledge. In the section on asymmetric impact of the action on fixed costs, we allow for firms' fixed costs to be affected differently and for uncertainty over the exact impact the action will have on fixed costs.

We will denote the strategy space of firm $i$ in the underlying competition games as $S_{i}$, which we assume is independent of the number of firms $(n)$, and denote a pure strategy for firm $i$ as $s_{i} \in S_{i}$. We will then refer to all firms other than some given firm $i$ as $-i$ and use $s_{-i}$ to denote the vector of all firms' strategies other than firm $i$. Firm $i$ 's profits are then $\pi_{i}\left(s_{i}, s_{-i}\right)$. For firm $i$ a strategy $s_{i}$ is the best response to $s_{-i}$ (denoted $\left.s_{i}^{*}\left(s_{-i}\right)\right)$ if $\pi_{i}\left(s_{i}, s_{-i}\right)>\pi_{i}\left(s_{i}^{\prime}, s_{-i}\right)$ for 
all $s_{i}^{\prime} \in S_{i}$. Standard conditions then ensure that there exists a unique Nash equilibrium in the pure strategies of the underlying competition game between $n$ firms and the resulting equilibrium strategies will be denoted as $s_{i}^{*}(n)$, where $\pi_{i}\left(s_{i}^{*}(n), s_{-i}^{*}(n)\right) \geq \pi_{i}\left(s_{i}(n), s_{-i}^{*}(n)\right)$ for all $s_{i} \in S_{i}$.

\subsection{A Profitable "Raising Fixed Costs" Strategy}

Define the base line fixed costs, $\underline{F}$, as the level of fixed costs in the absence of any cost-raising strategies. The level of $\underline{F}$ will determine the maximum number of firms which could be accommodated in the industry and we assume that $\underline{F}>0 .^{2}$ It follows that there must be an endogenous maximal number of firms, $n^{*}$, that can be in the industry even if fixed costs remain unchanged. Let $\pi\left(n^{*}\right)$ be the resulting per-firm gross profit before fixed costs (i.e. $\pi\left(n^{*}\right)=\pi_{i}\left(s_{i}^{*}\left(n^{*}\right), s_{-i}^{*}\left(n^{*}\right)\right)$. To simplify notation, we will assume that if a firm is indifferent between whether or not to produce, it will opt not to do so. We are interested in determining when it is profitable for firm 1 to take the action to raise fixed costs. Initially, we will assume that the action results in a specific level of fixed costs and in Proposition 1 provide a general sufficient condition for firm 1 to then profit from taking the action. We then allow for the impact of the action to be either endogenously or exogenously determined.

Proposition 1. Consider a market with base line fixed costs $\underline{F}>0$ and $n^{*}$ firms. As long as it subsequently remains in the market, a sufficient condition for firm 1 to profit from taking an action which raises fixed costs just high enough such that the equilibrium with $n^{*}$ firms is no longer viable and one firm is excluded, is that per-firm profits, $\pi\left(n^{*}\right)$, are convex in the number of firms.

Proof. Assume free entry and define $n^{*}$ as above. In this case $\underline{F} \geq \pi\left(n^{*}+1\right)$, hence the following inequality relating to current profits of $\pi\left(n^{*}\right)-\underline{F}$ must hold:

$0<\pi\left(n^{*}\right)-\underline{F} \leq \pi\left(n^{*}\right)-\pi\left(n^{*}+1\right)$.

If firm 1 could take an action which increases fixed costs to $\hat{F}(n)=\pi\left(n^{*}\right)$ to drive out one further firm, profits would be given by

$\pi\left(n^{*}-1\right)-\hat{F}(n)=\pi\left(n^{*}-1\right)-\pi\left(n^{*}\right)$.

From equation (1) a sufficient (but not necessary) condition for this to be profitable is that

$\pi\left(n^{*}-1\right)-\pi\left(n^{*}\right)>\pi\left(n^{*}\right)-\pi\left(n^{*}+1\right)$,

which we can write as

$\frac{1}{2}\left[\pi\left(n^{*}-1\right)+\pi\left(n^{*}+1\right)\right]>\pi\left(n^{*}\right)$.

This is exactly the condition for $\pi\left(n^{*}\right)$ to be convex. Therefore, a sufficient condition for excluding a rival when 1 is that $\pi\left(n^{*}\right)$ is convex. 
For the majority of oligopoly models, per-firm profits are a convex function of the number of firms. This is, for example, true for all Cournot models and, as demonstrated in Appendix 2, for differentiated goods Bertrand models. The intuition is simple; essentially, when one more firm is added two things happen to the per-firm profits. Firstly, there are more firms sharing the total profits and secondly, with more firms, competition is more intense and hence the total profits are also decreased.

The precise implication of Proposition 1 depends upon a number of factors which will be addressed in turn in the subsequent subsections.

\subsection{Endogenous or Exogenous Increase in Fixed Costs}

Firstly, note that for $n^{*}>2$, Proposition 1 (with base line fixed costs replaced by $F=\hat{F}\left(n^{*}-1\right)$ ) continues to apply to further reductions in the number of firms below $n^{*}-1$. It then crucially matters whether the size of the increase in fixed costs arising from a cost-raising strategy is endogenously or exogenously determined.

Corollary 1. Where the size of the increase in fixed costs is completely endogenous, firm 1 would choose to raise fixed costs to the lowest level of $F$ such that $\pi(2)-\underline{F}-F=0$.

In other words, fixed costs would be raised all the way to the point where only one firm remains active.

Corollary 2. If the size of the increase in fixed costs is endogenous, but has an upper bound at $\bar{F}$ where $\pi(r)<\underline{F}+\bar{F}<\pi(r-1)$ and $1<r<n^{*}$, total fixed costs would be raised to $\pi(r)$ and no further.

Here, fixed costs are raised such that as many firms as possible are excluded, with the fixed cost set so as to just exclude the marginal firm, similar to the following corollary.

Corollary 3. If the amount by which fixed costs can be raised is exogenous and results in total fixed costs of $F^{e}$ where $\pi(r)$, firm 1 would take the action to raise fixed costs if and only if $F^{e}>F^{*}(n)$ where $F^{*}(n)$ is the level of fixed costs such that $F^{*}(n) \equiv \pi_{i}\left(s_{i}^{*}(r-1), s_{-i}^{*}(r-1)\right)-\pi_{i}\left(s_{i}^{*}\left(n^{*}\right), s_{-i}^{*}\left(n^{*}\right)\right)$.

In other words, firm 1 would take the action to raise fixed costs to this level unless this is so costly that it removes the gains from excluding a rival. In the latter case firm 1 prefers the Nash equilibrium with $n^{*}$ firms and base line fixed costs. In the section on symmetric duopoly Cournot competition we compare $F^{*}(2)$ to $\hat{F}=\pi(2)$.

\subsection{Asymmetric Impact of the Action on Fixed Costs}

We initially assumed that all firms' fixed costs were raised equally; however, it also follows that the incentive to raise fixed costs may still exist even if the firm's own fixed costs rise more than its rivals, either because the action affects the firms differently or due to an additional cost involved in taking the action. To see this, using subscripts to distinguish between firm 1 and its rivals $^{\prime} j \neq 1$, it follows from Proposition 1 that firm 1 can exclude a rival if 
$\hat{F}(n) \leq F_{j}$ where $\hat{F}(n)=\pi_{j}\left(s_{j}^{*}(n), s_{-j}^{*}(n)\right)$. This is profitable for firm 1 as long as the action raises its own fixed costs such that $F_{1} \leq F^{*}(n)$ where $F^{*}(n)=\pi_{1}\left(s_{1}^{*}(n-1), s_{-1}^{*}(n-1)\right)-\pi_{1}\left(s_{1}^{*}(n), s_{-1}^{*}(n)\right)$, and this allows for the possibility that $\hat{F}(n) \leq F_{j}$. Furthermore, this range also allows for some degree of uncertainty over the exact impact the action will have on fixed costs, for example the final cost of the vexatious litigation.

\subsection{Raising $F$ as a Credible Commitment to Remain in the Industry - Forward Induction}

Crucial to Proposition 1 is the assumption that the firm that takes the action to raise fixed costs will remain in the industry. If firm 1 believes that raising fixed costs is followed by the exclusion of a rival, then raising fixed costs is optimal; however, if firm 1 believes that raising fixed costs is followed by any other equilibrium in the competition subgame then it would prefer to not take this action. This establishes that there is a multiplicity of subgame perfect equilibria.

As is well known, subgame perfection is not always a sufficiently strong equilibrium refinement to rule out all implausible equilibria. Note that the equilibrium with no cost-raising is based on firm 1's belief that all its rivals would respond to firm 1 raising costs by still choosing to produce; however, its rivals would only ever do this if they believed that firm 1 would follow raising costs by exiting the market. Such beliefs do not seem sensible, but subgame perfection does not rule out irrational beliefs. To do so we need to employ the reasoning behind forward induction.

Forward induction requires a firm to rationalise a prior move of a rival. Let the action be raising fixed costs to $\pi(r) \leq F$. In this case, firm 1's rivals must consider what could have motivated firm 1 and what subsequent move by firm 1 could make that action rational. In this case, firm 1's rivals can only rationalise the strategic choice of a higher $F$ by firm 1 choosing $s_{1}^{*}(r-1)$. More formally, we can refine the set of equilibria using forward induction. If firm 1 intended to follow raising fixed costs by exiting, it would have done better by not taking the action and instead choosing $s_{1}^{*}(r)$, as $\pi(r)-\underline{F}>0$. This leaves firm 1's rivals with only one possible inference from observing firm 1 taking the action to raise fixed costs, namely that firm 1 plans to choose $s_{1}^{*}(r-1)$ and in this case the best reply is for one of firm 1's rivals to exit. Given the beliefs of firm 1's rivals, firm 1's choice is between not taking the action to raise fixed costs, leading to profits of $\pi(r)-\underline{F}$, and raising rivals' fixed costs, leading to it earning $\pi(r-1)-\pi(r)$. From Proposition 1 the optimal choice for firm 1 is therefore to raise fixed costs.

The benefit of using forward induction is that it directly focuses on the inference that firm 1's rivals may make from observing the behaviour of firm 1. The key insight is that a "raising fixed costs" strategy makes no sense, unless the firm which does so also plans to exclude rivals from the market. We can think of firm 1's choice to raise the rivals' costs as including a communication about its strategy in the competition subgame. ${ }^{3}$ The inferences and resulting actions are clearest when firm 1 is raising fixed costs to exclude a single rival and thus monopolise the market; however, it also applies more generally for $n>2$ where raising fixed costs provides the 
commitment that firm 1 will remain in the market and at least one of its rivals is excluded, albeit with the potential for coordination issues over which rival this will be.

\subsection{Exclusion at a Lower Level of $F$}

Finally, in Proposition 1, firm 1 needs to raise $\hat{F}$ to $\pi\left(n^{*}\right)$ to exclude a rival; however, in certain settings it may not be necessary to raise fixed costs so high. This is because, as outlined earlier, under forward induction by raising fixed costs firm 1 can credibly commit to choosing $s_{1}^{*}\left(n^{*}-1\right)$; however, note that this means that one of firm 1's rivals will be excluded from the market if $F=\pi_{i}\left(s_{i}^{*}\left(n^{*}-1\right), s_{-i}^{*}\left(s_{i}^{*}\left(n^{*}-1\right)\right)\right)$. As we will illustrate in the next section, since under Cournot competition firms' strategies in the competition subgame are strategic substitutes, this level of $F$ will be below ${ }^{4} \hat{F}=\pi\left(n^{*}\right)$.

Overall, combining Proposition 1 with the above discussion of forward induction, a firm with the ability to raise fixed costs both for itself and its rival would have an incentive to do so for a certain range of resultant levels of fixed costs. If firm 1 could choose not just to raise fixed costs, but also to set the level, then it would raise them just sufficiently enough to enable it to monopolise the market.

\section{Application to Specific Oligopoly Models}

In this section we will apply the general model developed earlier to several specific oligopoly models. The last three subsections of this section will consider Cournot duopoly competition. This allows us to illustrate the range of levels of fixed costs for which raising the fixed costs is a profitable strategy and to extend the analysis by allowing for the firm that raises fixed costs to have higher marginal costs and a first-mover advantage in the product market. Before that, we briefly consider Bertrand competition with homogenous products and describe how high a firm would be willing to raise fixed costs in this setting.

\subsection{Bertrand Competition with Homogenous Products}

The analysis of this case follows directly from interpreting the fixed costs in the Dasgupta and Stiglitz (1988) model described in section on related literature as being strategically determined. Here, from the results of our general model, firm 1 will be willing to raise fixed costs to high levels since competition is otherwise so intense. More specifically, with $n \geq 2$ and $\underline{F}=0$, $\pi_{i}\left(p_{i}^{*}(n), p_{-i}^{*}(n)\right)=0$ and it follows that $F^{*}(2)$ is equal to the monopoly profits. Therefore, using the above forward induction argument, firm 1 would want to raise fixed costs as long as these remain below this level.

\subsection{Symmetric Duopoly Cournot Competition}

In the section on the general model we showed that in a wide range of oligopoly models raising fixed costs just sufficiently so that a rival is excluded is a profitable strategy. Consider symmetric Cournot duopoly competition with base line fixed costs $(0 \leq \underline{F})$ where $q^{c}$ is the symmetric Cournot duopoly 
equilibrium output. Here, following the earlier analysis, it will certainly be profitable for firm 1 to raise fixed costs to $\hat{F}(2)=\pi_{i}\left(q^{c}, q^{c}\right)$ and exclude firm 2 . In this subsection we examine symmetric duopoly Cournot competition further to consider the range of levels of fixed costs for which raising fixed costs is a profitable strategy. More specifically, how far below $\hat{F}(2)$ will it be possible for firm 1 to exclude firm 2 and how far above $\hat{F}(2)$ would it be willing to go to achieve this objective? In the next subsection we consider Cournot competition between firms that differ in marginal costs and consider the possibility that the less efficient firm can raise fixed costs to exclude its more efficient rival. Finally, in the last subsection we allow firm 1 to have a first-mover advantage in its output decision.

Denote the monopoly level of output as $q^{m}$. Standard conditions ensure that $2 q^{c}>q^{m}>q^{c}$, i.e. industry output is higher with two active firms than with a monopoly. Define the level of fixed costs above which the best reply to the monopoly output level by a rival is not to produce and hence avoid the fixed costs as

$\tilde{F} \equiv \pi_{i}\left(q_{i}^{*}\left(q^{m}\right), q^{m}\right)$

For low levels of fixed costs, $0 \leq F \leq \tilde{F}$, the Cournot equilibrium is the unique equilibrium, whereas for $\tilde{F} \leq F \leq \bar{F}$ (where $\bar{F}$ is the level of fixed costs above which no firm is profitable) there exists a $q^{\prime} \in\left[q^{c}, q^{m}\right]$ such that $F=\pi_{i}\left(q_{i}^{*}\left(q^{\prime}\right), q^{\prime}\right)$. Therefore, for all $q \in\left[q^{\prime}, q^{m}\right]$ the best reply to $q$ is to produce nothing. The best reply to the rival producing nothing is then $q^{m}$.

As suggested earlier, since quantities are strategic substitutes under Cournot competition, it must be the case that $\tilde{F}$ (see Appendix 3 for a formal demonstration). Furthermore, it follows from Proposition 1 that raising fixed costs to $\tilde{F} \leq F$ will be profitable.

The intuition can be explained using a best reply diagram. Figure 1 illustrates the case where fixed costs are such that $\tilde{F}$ and therefore when firm $i$ produces above $q^{\prime}$, where $q^{\prime}<q^{m}$, firm $j^{\prime}$ s best reply is to produce nothing. There are then three possible equilibria: two where only one firm is active and one in which both firm 1 and 2 are active (however, forward induction results in a unique prediction of only firm 1 being active, see note 4).

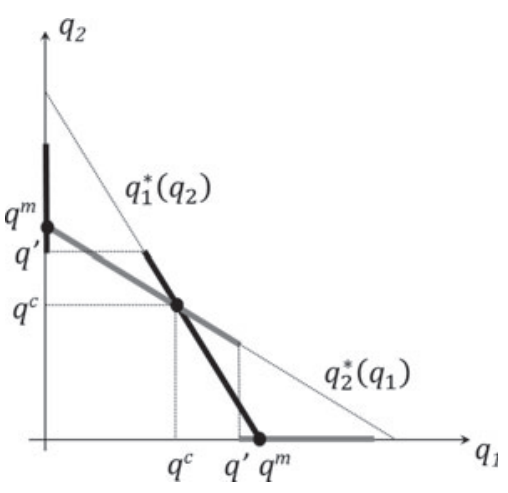

Figure 1. Best reply diagram for $\tilde{F}<F<\hat{F}(2)$. 
Starting out with the set of equilibria shown in Figure 1, if the fixed costs were increased sufficiently, it is clear that eventually (above $\hat{F}(2)$ ) the Cournot equilibrium would fail to exist.

Now consider how far above $\hat{F}(2)$ firm 1 would be willing to go to exclude firm 2. From earlier, there exists a level of fixed costs $F^{*} \equiv \pi_{i}\left(q^{m}, 0\right)-\pi_{i}\left(q^{c}, q^{c}\right)$ such that, for $F$, firm $i$ prefers the monopoly equilibrium with positive fixed costs and $q_{i}=q^{m}$ to the Cournot equilibrium with zero fixed costs. On the other hand, for $F^{*}$, firm $i$ prefers the Cournot equilibrium with baseline fixed costs to the monopoly equilibrium with fixed costs raised and $q_{i}=q^{m}$. Here, even being a monopolist does not compensate firm 1 for the cost increase.

Bringing together the analysis in this section, the following proposition outlines the complete range of fixed cost levels for which firm 1 can profitably exclude firm 2.

Proposition 2. If firm 1 can raise fixed costs such that $\tilde{F} \leq F<F^{*}$ (where $\tilde{F}<\hat{F}(2)$ and $\left.F^{*}<\bar{F}\right)$ it will be able to profitably exclude firm 2.

\subsection{Excluding a More Efficient Firm}

In the previous analysis we assumed that, apart from their ability to raise fixed costs, firms were otherwise identical. It is evident that our results hold if the firm that can take the action to raise fixed costs also has a marginal cost advantage; however, recent policy concerns in the EU have centred around the exclusion of a firm which is at least an "as-efficient competitor", see for example Vickers (2005). In Appendix 4 we show in a Cournot duopoly setting with linear demand that a firm with a marginal cost disadvantage can exclude a more efficient rival as long as the degree of cost asymmetry is not too large. Thus, a more efficient firm being excluded from the market is a second source of inefficiency that could arise from a fixed-cost-raising strategy.

\subsection{First-Mover Advantage in the Product Market}

In all of the above analysis we have assumed that firms make their pricing or output decisions simultaneously. We now relax this and allow firm 1 to be a Stackelberg leader in its output decision. Following the earlier analysis, here it will remain the case that firm 1 will be able to exclude firm 2 by raising $F$ above $\tilde{F}$ exactly as defined in the previous subsection on symmetric duopoly Cournot competition; ${ }^{5}$ however, the difference now is in how far above this level firm 1 would be willing to raise $F$ to exclude firm 2 . There now exists a level of fixed costs $F^{* *} \equiv \pi_{1}\left(q^{m}, 0\right)-\pi_{1}\left(q^{m}, q^{*}\left(q^{m}\right)\right)$ such that for $F^{* *}$ firm 1 prefers the Stackelberg equilibrium with baseline fixed costs to the monopoly equilibrium with fixed costs raised and $q_{1}=q^{m}$. Note that the standard result that firm 1s profits are higher as a Stackelberg leader ensures that $F^{* *}$ is lower than $F^{*}$, as defined in the subsection on symmetric duopoly Cournot competition. This means that under Stackelberg competition the range of fixed costs for which firm 1 can exclude firm 2 is narrower than that in Proposition 2 under Cournot competition with simultaneous output decisions. In the former, firm 1 has higher profits in the status quo and so is less willing to push up fixed costs to exclude a rival. On the other hand, this alternative 
source of asymmetry also means that it is no longer necessary that firm 1 alone has the ability to raise fixed costs. Furthermore, once it has a first-mover advantage in the product market, firm 1 has no need to communicate its intention in the competition subgame. Hence, here there is no need to rely on the forward induction argument to support a credible fixed-cost-raising strategy.

\section{Conclusion}

This article has argued that across many sectors there is a wide range of avenues by which a well placed firm can potentially raise rivals' fixed costs. We then demonstrated that it can be a profitable strategy for such a firm to exclude its rivals even if its fixed costs are affected as much (or even more) than those excluded and even if it is less efficient. Strategies which "merely" increase fixed costs can therefore harm economic welfare and should not be dismissed from competition and regulatory authority scrutiny. Moreover, this insight generalises to cases where both fixed and variable costs are raised and cautions competition agencies against ignoring the implications of the first of these effects. Raising rivals' fixed costs may also be more durable because it is more likely to lead to an exit and to alter entry conditions permanently.

In Appendix 1 we also provide an indication of the type of sectors where we should be particularly concerned about harm due to fixed-cost-raising strategies. Returning to the specific examples discussed, we can point to several further policy implications arising from this article. Firstly, firms really do have an incentive to gold-plate regulation and regulatory procedures, and an incentive for incumbent firms to remove so-called red tape of regulators and governments may not exist. This has important implications for the procedures regulators and governments use for consulting about reforms. As suggested by the Office of Fair Trading (2002), regulation can have an adverse effect on competition in certain scenarios and therefore policy makers should consider this impact on the industry. Regulatory impact assessments should be alert to the possibility that firms may be appearing to argue against their own narrow best interests not because they are public spirited, but because this can confer a benefit to them by reducing the number of competitors. Such concerns are particularly relevant in situations where close connections with the firms make the regulator prone to regulatory capture and thus likely to act in the best interest of firms rather than consumers.

Secondly, courts and authorities should be alert to the possibility that vexatious litigation can amount to an abuse of dominance and hence be caught by competition law. Moreover, competition agencies should in particular be alert to allegations about abusive threats of intellectual property litigation that arise from horizontal rivals. Thirdly, with respect to the examples where the fixed costs of essential inputs are raised, the main message in this paper is that even if many of these strategies do not affect marginal costs they can still have significant anti-competitive effects.

Finally, this paper has focused on the strategic increase in fixed costs to deter entry or force a rival to exit the industry; however, as suggested by Durham et al. (2004), there is at least one possible alternative motive for a "raising fixed costs" strategy which is worth noting and may provide avenues 
for further research. If at least part of the fixed costs is sunk, then firms may prefer to stay in the industry and make losses rather than immediately exit the industry. However, a change in industry conduct, i.e. a move towards more collusive behaviour would potentially allow all firms to continue to make positive profits. Therefore, the motive for raising industry wide fixed costs could be to change conduct in the industry rather than to attempt to exclude. This is similar to the rationale for RRC in Mason (2002) where it is shown in a dynamic setting that a symmetric increase in variable costs can be profitable for all firms if it leads to a reduction in the intensity of competition. Furthermore, an experiment conducted by Durham et al. (2004) found evidence that, when large fixed costs were present, price signalling behaviour took place in an attempt to reduce competition and enable firms to remain profitable.

\section{Notes}

1. Consistent with the examples described below, we focus on fixed costs that are avoidable for any firm that decides not to produce. This is in contrast to the stream of literature initiated by Sutton (1991) which examines how the escalation of sunk costs affects market concentration.

2. In general, except in the specific case of homogeneous product Bertrand competition (see the section on Bertrand competition with homogenous products), $\underline{F}=0$ provides a very different result to Proposition 1. Namely, that for $n>2$ it is then never worthwhile to raise rivals' fixed costs. The intuition for this result follows from the fact that with free entry there is nothing restricting the number of firms. For any given initial finite $n$, any firm contemplating raising fixed costs to reduce the number of firms to $n-1$ is essentially doing it not from $n$ but from an infinitely larger number. Even though the profit of each firm is very small when $n$ is very large, so is the incremental increase in profits from reducing the number of firms by one. This result only occurs in the limit when there is room for infinitely many firms.

3. For the use of forward induction for this purpose, see for example Bagwell and Ramey (1996).

4. Note that here, there will still be an equilibrium in which firm 1 takes the action to raise fixed costs and $s_{i}=s_{i}^{*}\left(n^{*}\right) \forall i$; however, using forward induction, if firm 1 intended to choose $s_{1}^{*}\left(n^{*}\right)$ it never makes any sense for firm 1 to raise fixed costs. Thus, observing raised fixed costs, firm 1 's rivals must rule out $s_{1}=s_{1}^{*}\left(n^{*}\right)$.

5. This is the blockaded entry case described in model by Dixit (1979) of entry barriers under Stackelberg competition. He also describes how entry can be deterred at lower levels of fixed costs under the assumption of the Sylos postulate, where the leader can commit to a given level of output regardless of whether or not entry occurs.

6. The comment by Sawyer (2001) also suggests that their results are applicable beyond NAFTA.

7. The broader organisational literature on corporate political activity is summarised in Hillman, Keim, and Keim (2004) and Shaffer (1995). These surveys demonstrate that firms spend substantial resources on political lobbying activities and that this is not just restricted to the US, but extends to many other countries (see Hillman, Keim, and Keim, 2004, 838).

8. These are sometimes known as spurious litigation, nuisance suits or sham suits.

9. See Gavil, Kovacic and Baker $(2008,1081)$ for a summary of important past US cases.

10. Where each party pays their own legal costs irrespective of the outcome (e.g. the US), there is clearly more scope to RRC than where the loser pays (e.g. most EU member states).

11. See Bloom, Gundlach and Cannon (2000) for an overview.

12. Land banks held by major grocery chains were one of the issues considered in the 2006 UK Competition Commission market inquiry into the groceries market. See http://webarchive. nationalarchives.gov.uk/20140402141250/www.competition-commission.org.uk/our-work/direc tory-of-all-inquiries / groceries-market-investigation-and-remittal / final-report-and-appendicesglossary-inquiry.

13. Similar effects can arise in connection with other kinds of deception such as the creation and marketing of a "version of software that is not cross-platform compatible. The costs of correcting unexpected compatibility problems are almost entirely fixed. 


\section{References}

Bagwell, Kyle, and Garey Ramey. 1996. Capacity, Entry, and Forward Induction. RAND Journal of Economics 27 (4): 660-680.

Bartel, Ann P., and Lacey G. Thomas. 1987. Predation Through Regulation: The Wage and Profit Effects of the Occupational Safety and Health Administration and the Environmental Protection Agency. Journal of Law and Economics 30 (2): 239-264.

Bloom, Paul N., Gregory T. Gundlach, and Joseph P. Cannon. 2000. Slotting Allowances and Fees: Schools of Thought and the Views of Practicing Managers. Journal of Marketing 64 (2): 92-108.

Comanor, William S., and Thomas A. Wilson. 1974. Advertising and Market Power. Cambridge, MA: Harvard University Press.

Dasgupta, Partha, and Joseph E. Stiglitz. 1988. Potential Competition, Actual Competition, and Economic Welfare. European Economic Review 32 (2-3): 569-577.

Depken, Craig A. II, and Jon M. Ford. 1999. NAFTA as a Means of Raising Rivals' Costs. Review of Industrial Organization 15 (2): 103-113.

Dixit, Avinash. 1979. A Model of Duopoly Suggesting a Theory of Entry Barriers. Bell Journal of Economics 10 (1): 20-32.

Durham, Yvonne, Kevin McCabe, Mark A. Olson, Stephen Rassenti, and Vernon Smith. 2004. Oligopoly Competition in Fixed Cost Environments. International Journal of Industrial Organization 22 (2): 147-162.

Gavil, Andrew I., William E. Kovacic, and Jonathan B. Baker. 2008. Antitrust Law in Perspective: Cases, Concepts and Problems in Competition Policy. 2nd ed. St. Paul, MN: West Academic Publishing.

Hilke, John C., and Philip B. Nelson. 1984. Noisy Advertising and the Predation Rule in Antitrust Analysis. American Economic Review, Papers and Proceedings 74 (2): 367-71.

Hilke, John C. 1989. Strategic Behaviour and Attempted Monopolization: The Coffee (General Foods) Case. In The Antitrust Revolution, edited by John E. Kwoka and Larry J. Glenview, IL: Scott, Foresman and Company.

Hillman, Amy J., Gerald D. Keim, and Douglas Schuler. 2004. Corporate Political Activity: A Review and Research Agenda. Journal of Management 30 (6): 837-857.

Lerner, Josh. 1995. Patenting in the Shadow of Competitors. Journal of Law and Economics 38 (2): 463-495.

Mason, Robin. 2002. Cost-raising Strategies in a Symmetric, Dynamic Duopoly. Journal of Industrial Economics 50 (3): 317-335.

McChesney, Fred S. 1997. Money for Nothing. Cambridge, MA: Harvard University Press.

McWilliams, Abagail, David D. Van Fleet, and Kenneth Cory. 2002. Raising Rivals' Costs Through Political Strategy: An Extension of the Resource-based Theory. Journal of Management Studies 39 (5): 707-723.

Michaelis, Peter. 1994. Regulate Us, Please! On Strategic Lobbying in Cournot-Nash Oligopoly. Journal of Institutional and Theoretical Economics 150 (4): 693-709.

Office of Fair Trading (OFT). 2002. Guidelines for Competition Assessment - A Guide for Policy Makers Completing Regulatory, 876. No: Impact Assessment.

Oster, Sharon. 1982. The Strategic Use of Regulatory Investment by Industry Sub-groups. Economic Inquiry 20 (4): 604-618.

Prendergast, Canice. 1998. What Happens Within Firms? A Survey of Empirical Evidence on Compensation Policies. In Labor Statistics Measurement Issues. Studies in Income and Wealth, edited by John Haltiwanger, Marilyn E. Manser and Robert H. Topel. vol. 60, 329-354. Chicago: University of Chicago Press.

Rogerson, William P. 1984. A Note on the Incentive for a Monopolist to Increase Fixed Costs as a Barrier to Entry Quarterly Journal of Economics 99 (2): 399-402.

Rubinfeld, Daniel L., and Robert Mannes. 2005. The Strategic Use of Patents: Implications for Antitrust. In Antitrust, Patents and Copyright: EU and US Perspectives, edited by Francois Lévêque and Howard Shelanski, 85-102. Cheltenham, UK: Edward Elgar Publishing.

Salop, Steven C., and David T. Scheffman. 1983. Raising Rivals' Costs: Recent Advances in the Theory of Industrial Structure. American Economic Review 73 (2): 267-271.

Salop, Steven C., and David T. Scheffman. 1987. Cost-raising Strategies. The Journal of Industrial Economics 36 (1): 19-34.

Sawyer, W. Charles. 2001. NAFTA as a Means of Raising Rivals' Costs: A Comment. Review of Industrial Organization 18 (1): 127-131. 
Shaffer, Brian. 1995. Firm-level Responses to Government Regulation: Theoretical and Research Approaches. Journal of Management 21 (3): 495-514.

Shaffer, Greg. 2005. Slotting Allowances and Optimal Product Variety. The B.E. Journal of Economic Analysis \& Policy 5 (1): Article 3. http://www.degruyter.com/view/j/bejeap.2005.5.issue-1/ bejeap.2005.5.1.1083/bejeap.2005.5.1.1083.xml?format=INT.

Sutton, John. 1991. Sunk Costs and Market Structure: Price Competition, Advertising, and the Evolution of Concentration. Cambridge, MA: MIT Press.

Tharp, John J. 1990. Raising Rivals' Costs: Of Bottlenecks, Bottled Wine, and Bottled Soda. Northwestern University Law Review 84 (1): 321-374.

Vickers, John. 2005. Abuse of Market Power. The Economic Journal 115 (504): 244-261.

Williamson, Oliver E. 1968. Wage Rates as a Barrier to Entry: The Pennington Case in Perspective. Quarterly Journal of Economics 82 (1): 85-116.

\section{Appendix 1. Ways of Raising Fixed Costs}

Here we will outline a range of strategies that a firm which is well placed, due to the reasons outlined in the section on the set-up and assumptions, could adopt to raise all of the firms' fixed costs. The order in which these strategies will be introduced matches their ability to also raise variable costs, ranging from the most to the least likely.

\section{Costly Rules and Regulations}

There is an extensive and well established literature on lobbying for regulation; see, for example, McWilliams, Van Fleet, and Cory (2002) for a large number of examples of regulation which increases rivals' costs and Shaffer (1995) for a more general survey of the interaction between firms and governments when it comes to regulation.

While typically seen as a means of raising variable costs through increased tariffs, some costs related to trade policy can be fixed. For example, Depken and Ford (1999) consider the costs of obtaining a tariff reduction for firms trading within the North American Free Trade Agreement (NAFTA). ${ }^{6}$ They model firms as facing a trade-off between incurring high fixed application costs to obtain a tariff and a marginal cost reduction or accepting the high tariff and consequently having high marginal but low fixed costs; however, clearly exiting the market is also an option. Consider the case where a firm is not viable without the tariff reduction; in this case rivals successfully lobbying for an increase in the fixed application costs can leave exiting as the only viable strategy for this firm.

Another example arises from increases in the compliance costs. Such costs are typically independent of output levels and hence represent a genuine increase in fixed costs. Many different forms of regulation impose significant compliance costs on firms competing within, or considering entering, an industry. ${ }^{7}$ For example, Bartel and Thomas (1987) show how both the Occupational Safety and Health Administration and the Environmental Protection Agency have been used as means to predate by RRC.

\section{Vexatious Litigation}

Litigation with the primary aim of disadvantaging the defendant rather than to right a wrong offers an alternative way of raising a rival's fixed costs. Most jurisdictions recognise that a dominant firm could abuse its position through vexatious litigation ${ }^{8}$ and hence allow a victim's claims to be brought before the courts, but courts are reluctant to allow such cases because firms and individuals have a fundamental right of access to a judge. ${ }^{9}$ Although it may be possible for a victim of this form of RRC to defeat it in court, establishing that the litigation is truly vexatious is clearly very demanding. Hence vexatious litigation remains a plausible strategy to raise a rival's fixed costs.

While the success of this strategy depends to some extent on cost allocation rules, at best only the direct costs of litigation can be shifted to the losing party. ${ }^{10}$ These may be a relatively small part of the full opportunity cost of defending a case. Additional costs such as court fees, expert advise and the opportunity costs of the officers and other staff of the company tied up in the court proceedings are typically not recoverable and are almost invariably fixed. Hence, even in 
jurisdictions with a loser pays policy, vexatious litigation may still be able to raise costs significantly.

This form of behaviour is more likely to be a problem in industries in which intellectual property rights are particularly important, for example the pharmaceutical and biotechnology industries, because in these industries threats of action and action against infringement are often observed. There is also some evidence that firms in their patenting decisions may plan both offensively and defensively for vexatious litigation. Work on patent thickets suggests that a firm's patenting behaviour may be influenced by future litigation possibilities aimed at RRC (see, for example, Rubinfeld and Maness, 2005). Defensively, Lerner (1995) shows that firms with high litigation costs try to avoid patenting in areas where there are rivals and in particular where rivals with low-litigation costs have previously patented.

\section{Specialised Inputs}

As discussed earlier, a long-standing example of an RRC strategy is paying inflated wages to workers (Williamson, 1968). In a case brought in the 1960s against Pennington, a US mining firm, it was alleged that they had used a wage agreed with the labour union in order to RRC. The strategy of inflating wages at one firm would clearly not work if there was a ready supply of workers willing to take on work for rivals at non-inflated wages. Thus, the supply of workers has to be restricted. This could occur for a variety of reasons, for example because a particular skill is required. An obvious example of this would be sports stars, where the effect of one team paying inflated salaries is likely to be that others would have to match or lose players; however, in this case we also observe key players locked in through long-term contracts, making such key workers more of a fixed cost. While long-term labour contracts are unusual, long-term relationships through implicit contracts may be less so, especially with key personnel. For example, Prendergast (1998) points out that many of the incentive mechanisms used by firms require a long-term relationship between the firm and the worker. More directly, many incentive schemes for managers include fixed elements. The extent to which a firm could really hurt a rival by strategically over-paying workers is an unresolved empirical matter; however, where it is possible, at least part of the cost increase is likely to be in fixed costs. The next category describes a number of other scenarios where it is clear that essential inputs are have a fixed and limited supply.

\section{Competition for Capacity}

With the number of products available outstripping the space on supermarket shelves, competition for scarce shelf-space has increased. This scarcity has induced manufacturers to pay retailers slotting allowances, that is lump-sum payments, to secure their share of available shelf space. It is well recognised in the literature that the competition for space can lead to anti-competitive effects 11 and in particular that slotting allowances can be used as an RRC strategy. In Shaffer $(2005,3)$, "Slotting allowances raise rivals' costs because they are the means by which the dominant firm bids up the price of an essential input (the retailers' shelf space)". Furthermore, it is shown that the incentive to induce exclusion through slotting allowance is greater the closer substitutes products are, i.e. the more valuable the exclusion is.

While one could argue that these strategies should be grouped with the previous section, the benefit of keeping them separate is twofold. Firstly, the strategy solely affects fixed, not variable, costs. Secondly, it highlights sectors (e.g. large format retailing) for which the strategy is particularly relevant. As with slotting allowances, in such sectors the holding of land banks of sites in particularly well suited to locations which will raise the cost of entry or expansion of rival retailers. ${ }^{12}$ In addition, there will also be many other sectors where key inputs are a fixed cost and are also in short supply, for example the spectrum for mobile broadband provision.

\section{Advertising to Blur the Message}

There are cases where advertising can be used strategically to blur the message, either by blocking the message space, much like a slotting allowance with respect to physical space, or by drowning out the message of a rival. ${ }^{13}$ 


\section{M. Hviid and M. Olczak}

An example of the first type of strategy can be found in Tharp (1989-1990) who shows that the "Calendar Marketing Agreements" (CMA), used for example by Pepsi and Coca-cola in the US, to secure exclusive promotional services can RRC. The CMA works much like a slotting allowance in that it crowds out other retailers, although it possibly goes one step further by securing exclusivity for the retailer's advertising during specified periods.

The idea that the advertising of others creates "noise" in the market goes back to at least Comanor and Wilson (1974). Where one firm's advertising reduces the effectiveness of a rival's message, it is clear that a dominant firm by raising its expenditure on advertising can force others to either do the same or to exit. An example of this emerges from the US coffee market. Hilke and Nelson (1984, 1989) provide evidence that the dominant player, Maxwell House, used such a strategy when facing entry by another coffee maker, Folgers. A particularly interesting aspect of their strategy was that they chose their advertising to be as close to the entrants campaign as possible, thereby hoping to create confusion between the two brands, something which was likely to harm the incumbent the least.

\section{Summary of the Cost Raising Strategies}

The fixed costs referred to in this section have all been avoidable for a firm that exits the market and hence all have the capacity to exclude rivals. Furthermore, the strategies could be employed in a range of sectors, ensuring their economic relevance. Regulation is particularly relevant in industries where health and safety or environmental concerns are important. Vexations regulation is often linked to the use of intellectual property protection and hence relates particularly to the pharmaceutical industry and other heavy users of patent protection. Raising the costs of specialised inputs is particularly relevant in sports, but can also be expected in industries where talent is key, such as software development. Slotting allowances are particularly found in large format retailing such as supermarkets. Finally, some of the advertising strategies affect manufacturers of convenience goods.

\section{Appendix 2. Bertrand Model with Differentiated Products}

To consider the effect on the number of firms and hence the number of products in a differentiated goods oligopoly, the derived demand function must allow for the number of variants to vary. Consider the following quadratic utility function where the consumer has a preference for diversity:

$$
U\left(q_{0} ; q_{i}, i \in\{1, \ldots, N\}\right)=K+\alpha \sum_{i=1}^{N} q_{i}-\frac{\beta}{2} \sum_{i=1}^{N} q_{i}^{2}-\frac{\gamma}{2} \sum_{i=1}^{N} \sum_{j \neq i}^{N} q_{i} q_{j}+q_{0}
$$

where $\beta \geq \gamma, q_{0}$ is the composite outside good and $q_{i}$ is the $i$ th variant. Maximising (2.1) subject to a budget constraint yields the following set of linear demand functions:

$$
q_{i}=\frac{1}{\beta+\gamma(N-1)}\left[\alpha-\frac{\beta+\gamma(N-2)}{(\beta-\gamma)} p_{i}+\frac{\gamma}{(\beta-\gamma)} \sum_{j \neq i}^{N} p_{j}\right], \quad i \in[1, N] .
$$

Normalising marginal costs to zero, we can find the equilibrium price levels and hence the equilibrium profit as a function of the number of firms $N$ :

$$
\pi(N)=\alpha^{2} \frac{(\beta-\gamma)(\beta+\gamma(N-2))}{(\gamma(N-3)+2 \beta)^{2}(\beta+\gamma(N-1))}-F .
$$

The key question is whether this per-firm profit function is convex in the number of firms. Differentiate (2.2) twice to obtain 
$\frac{\partial^{2} \pi}{\partial N^{2}}=\frac{2 \alpha^{2} \gamma^{2}(\beta-\gamma)}{(\beta-\gamma+N \gamma)^{3}(2 \beta-3 \gamma+N \gamma)^{4}} \Psi$

where

$$
\begin{aligned}
\Psi & =\left[1+(N-2)\left(11-9 N+3 N^{2}\right)\right] \gamma^{3}+\left[37-34 N+9 N^{2}\right] \beta \gamma^{2} \\
& +[9 N-18] \beta^{2} \gamma+[3 \beta-2 \gamma] \beta^{2} .
\end{aligned}
$$

As each term in square brackets is positive for $N \geq 2$, it follows that here $\left(\partial^{2} \pi\right) /\left(\partial N^{2}\right)>0$. Hence, per-firm profits are convex in the number of firms so that the sufficient condition in Proposition 1 holds.

\section{Appendix 3. Proof that $\tilde{F}<\hat{F}$ for a Cournot Duopoly}

The best reply of firm $i$ to $q_{j}$ is given by the solution to

$\frac{\partial \pi_{i}\left(q_{i}, q_{j}\right)}{\partial q_{i}}=0$

Consider the profit of firm $i$ along its best reply function and note that this is decreasing in $q_{j}$ because

$\frac{\partial \pi_{i}\left(q_{i}^{*}\left(q_{j}\right), q_{j}\right)}{\partial q_{j}}=\frac{\partial \pi_{i}\left(q_{i}, q_{j}\right)}{\partial q_{i}} \frac{d q_{i}^{*}\left(q_{j}\right)}{d q_{j}}+\frac{\partial \pi_{i}\left(q_{i}, q_{j}\right)}{\partial q_{j}}=\frac{\partial \pi_{i}\left(q_{i}, q_{j}\right)}{\partial q_{j}}<0$.

Since $q^{m}>q^{c}$ it follows that $\pi\left(q_{i}^{*}\left(q^{m}\right), q^{m}\right)$.

\section{Appendix 4. Profitable Fixed Cost Raising by a Less Efficient Firm}

Consider Cournot competition between firms 1 and 2 with marginal production $\operatorname{costs} c_{1}>c_{2}$ and where as before only firm 1 can take an action to raise fixed costs. Assume inverse demand is given by

$p=a-b Q$

where $Q=q_{1}+q_{2}$ and $a>c_{1}$. Standard computations yield the following profits for the Cournot equilibrium:

$\pi_{i}\left(q_{i}^{c}, q_{j}^{c}\right)=\frac{\left(a-2 c_{i}+c_{j}\right)^{2}}{9 b}$

Alternatively, if firm $i$ is a monopolist its profit are given by

$$
\pi_{i}\left(q_{i}^{m}, 0\right)=\frac{\left(a-c_{i}\right)^{2}}{4 b}
$$

Following the earlier analysis, firm 1 will be willing to raise fixed costs to exclude firm 2 as long as F. A sufficient condition for firm 1 to be willing (as in the section on symmetric duopoly Cournot competition) to raise fixed costs beyond the level at which the duopoly is no longer viable is that 
$\pi_{1}\left(q_{1}^{m}, 0\right)>\pi_{1}\left(q_{1}^{c}, q_{2}^{c}\right)+\pi_{2}\left(q_{1}^{c}, q_{2}^{c}\right)$

To consider the impact marginal cost asymmetry has on the condition in (4.3), we can increase asymmetry holding average industry costs constant, i.e. $\left(c_{1}+c_{2}\right) / 2 \equiv c$ and therefore $c_{2}=2 c-c_{1}$. Then, using (4.1),

$\pi_{1}\left(q_{1}^{c}, q_{2}^{c}\right)+\pi_{2}\left(q_{1}^{c}, q_{2}^{c}\right)=\frac{\left(a+2 c-3 c_{1}\right)^{2}+\left(a+3 c_{1}-4 c\right)^{2}}{9 b}$

Using (4.2) and (4.4) it can then be shown that (4.3) holds as long as

$c_{1}+20\left(c_{1}-c\right)<a$

This condition is clearly satisfied in the symmetric case where $c_{1}=c$. Furthermore, as the left-hand side of (4.5) is increasing in $c_{1}$, there exists a level of $c_{1}>c$ such that (4.5) holds with equality. 